\title{
El jardín de Calixto y Melibea o ¿quién paga al ciudadano?
}

Pedro Luis Roás Martín, magistrado de la Sala de lo Contencioso-Administrativo del Tribunal Superior de Justicia de Andalucía

La concurrencia de responsabilidades en el ámbito de la protección del patrimonio histórico, como consecuencia de la coexistencia de competencias comunes en la materia, es un fenómeno frecuente. En la doctrina de nuestros tribunales nos encontramos con una tendencia creciente al reconocimiento de una responsabilidad común de las diferentes administraciones públicas en orden a la consecución de objetivos vinculados con la protección del patrimonio histórico y asunción conjunta de las consecuencias perjudiciales derivadas de su desatención o incumplimiento.

El propio Tribunal Constitucional en su sentencia de 31 de enero del año 1991, resolviendo los conflictos y recurso formulado contra la Ley de patrimonio histórico-artístico español, destacaba la competencia exclusiva del Estado en la defensa del patrimonio cultural, artístico y monumental español contra la exportación y la expoliación; así como en museos, bibliotecas y archivos de titularidad estatal, pero sin perjuicio de su gestión por parte de las comunidades autónomas. Y, bajo esta última premisa, ponía de manifiesto que diversos estatutos de autonomía venían a asumir competencias exclusivas en materia de patrimonio histórico, artístico, monumental y arqueológico, y en archivos, bibliotecas y museos, cuando no fueren de titularidad estatal, dejando siempre a salvo la competencia del Estado prevista en el anterior artículo 149.1.28 de la Constitución.

En esta tesitura, el Tribunal Constitucional afirmaba la existencia en este concreto ámbito de un auténtico fenómeno de competencias concurrentes, que se traducia en la presencia de una acción autonómica específica, pero reconociendo igualmente la del Estado en orden a la preservación del patrimonio cultural común, y también en todo aquello que precisare tratamientos generales o que hicieren menester aquella acción pública cuando los fines culturales no pudieran lograrse desde otras instancias (STC 48/1984).

Se hace preciso, por tanto, considerar un concepto amplio de cultura, categoría en la que se hallarian incardinados todos los bienes que, por su naturaleza, formasen parte de la cultura de un país y por tanto, un concepto genérico que hallaría plena cabida en el marco de las previsiones recogidas en el artículo 46 de la Constitución. Bajo tal premisa, afirma en otras numerosas sentencias el Tribunal Constitucional que la cultura es algo de la competencia propia e institucional, tanto del Estado como de las comunidades autónomas.

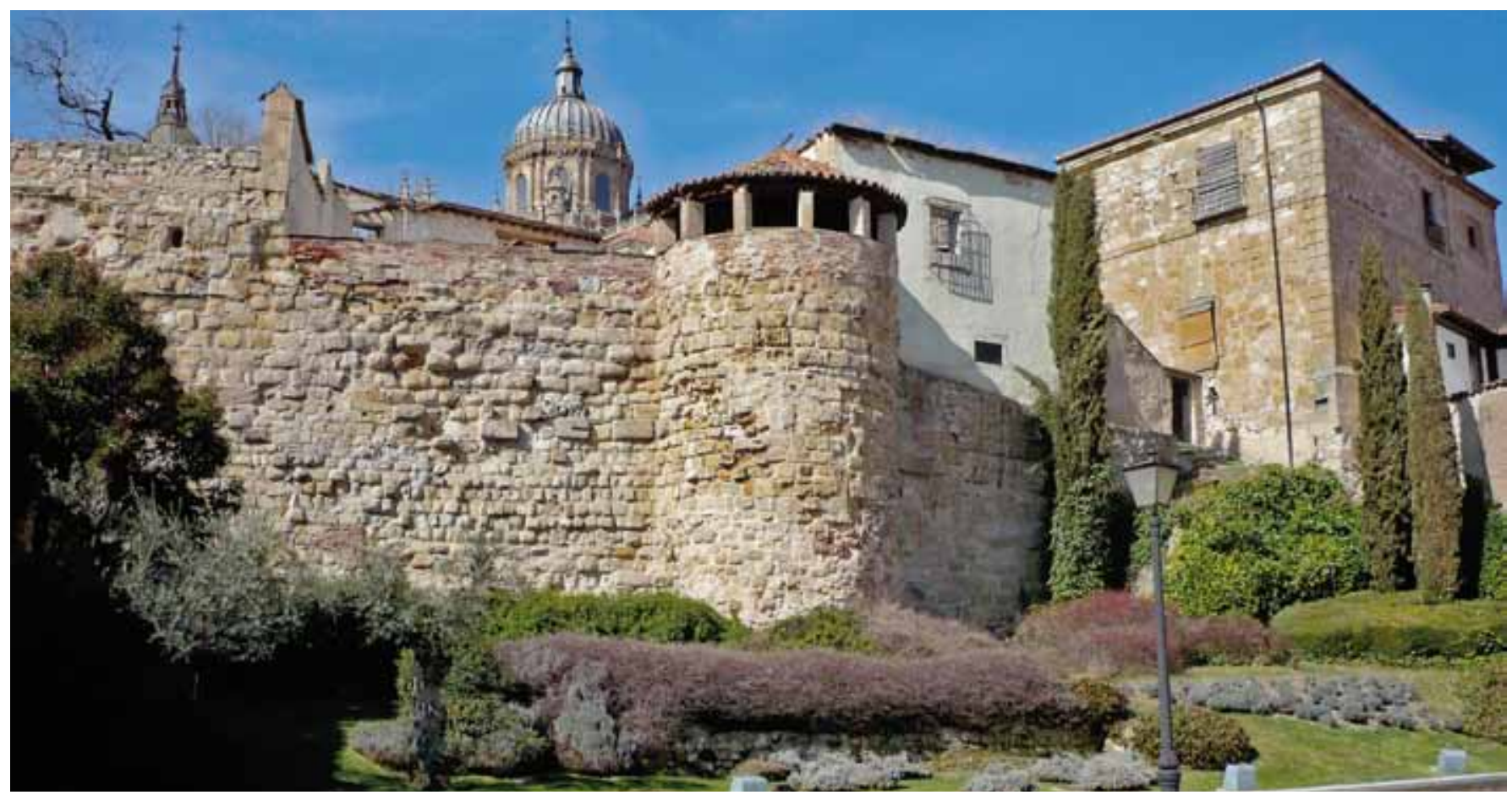

El huerto de Calixto y Melibea (en Salamanca) desde abajo. Foto: María Barrena 
La problemática se intensifica cuando hacen acto de presencia otros entes públicos, como los locales, pues pueden participar igualmente de competencias estrechamente vinculadas con la protección del patrimonio, tales como las derivadas del planeamiento urbanístico, concesión de licencias y deber de cooperación en materia de protección del patrimonio histórico. En este sentido, la doctrina de nuestros tribunales (como ejemplo la sentencia de 7 de octubre de 2003 de la Sala de lo Contencioso-Administrativo en Valladolid, del Tribunal Superior de Justicia de Castilla-León) apunta a la concurrencia de una pauta interpretativa de la normativa legal en el sentido más favorable siempre a la conservación del patrimonio histórico, reconociendo que los organismos protectores pueden separarse incluso, si ello fuera necesario, de las normas urbanísticas y de las licencias que hubieran otorgado otros organismos, a fin de adoptar e imponer las limitaciones que discrecionalmente estimen necesarias para tal fin.

También exhibe su importancia esta problemática en el marco de los deberes de conservación, sobre los que se suscitan cuestiones acerca de la titularidad del mencionado deber y de las consecuencias de su incumplimiento. Así, el supuesto analizado por la Sala de lo Contencioso-Administrativo del Tribunal Superior de Justicia de Murcia de 29 de septiembre del año 2000, acerca del deber de conservación de las administraciones, a tenor del artículo 36 de la Ley del patrimonio histórico español, que impone la obligación de conservación, mantenimiento y custodia de los bienes integrantes del patrimonio histórico español a sus propietarios y que llevó, en este caso, a concluir en la proclamación, aún a título subsidiario, de la competencia y responsabilidad de la Administración autonómica. Si bien los bienes a los que se referia el supuesto se integraban dentro del patrimonio histórico español, correspondería a la Administración autonómica el cumplimiento de la obligación de conservación, mantenimiento y custodia, ante la pasividad del Ministerio, siendo, en consecuencia, responsable la primera de actuar de forma subsidiaria conforme al apartado tercero del artículo 36 de la LPHE, que impone a la Administración competente, previo requerimiento a los interesados a fin de cumplir con las obligaciones descritas, ordenar su ejecución subsidiaria.

Pues bien, la misma problemática se plantea en relación con la responsabilidad patrimonial de las administraciones públicas, cuando todas ellas ostentan, directa o indirectamente, competencias en la materia, a fin de identificar cuál de ellas y en qué medida debiere soportar las consecuencias indemnizatorias derivadas de la apreciación de un supuesto constitutivo de tal naturaleza.

Véase que, en definitiva, ésta es la controversia que se analiza en las sentencias dictadas por la Audiencia Nacional, Sala de lo Contencioso-Administrativo, de 2 de julio de 2003, de 4, 11 y 29 de octubre y 21 de julio de 2004, y de 1 de julio de 2005, asi como en la sentencia de la Sala de Valladolid de lo ContenciosoAdministrativo del Tribunal Superior de Justicia de la comunidad de Castilla-León, de fecha de 6 de septiembre de 2006. Supuestos todos ellos en los que se analiza la responsabilidad del Estado y del Ayuntamiento de Salamanca por los daños ocasionados en diversos bienes como consecuencia del derrumbamiento sufrido en la muralla de Salamanca el 4 de junio del año 2000, en la zona en que se encontraba el torreón Ilamado de Calixto y Melibea. Responsabilidades concurrentes que derivarian, en caso del Ayuntamiento, del tramo de la muralla afectado por el derrumbamiento, pues sería colindante por su cara interna con el citado huerto, propiedad en parte de la corporación municipal; y, en el caso del Estado, al ser titular de cuatro tramos de la muralla de Salamanca, entre los que se hallaria el torreón afectado.

De este modo, se analizaria el ámbito de la competencia propia de cada una de las administraciones al respecto y su desatención o incumplimiento a fin de apreciar una situación constitutiva de responsabilidad por los diversos daños ocasionados. Y lo cierto es que se constata la responsabilidad concurrente de ambas administraciones, responsables cada una de ellas en parte de los daños ocasionados; y, en ambos casos, por el incumplimiento de aspectos necesariamente vinculados con el adecuado deber de conservación de la muralla. La responsabilidad municipal, dada la causa fundamental del hundimiento de la muralla, como consecuencia de la acumulación de agua de riego en el jardín de propiedad municipal; y, la responsabilidad del Estado que, por una parte, debía exigir de la Administración competente, en este caso la municipal, la adopción de medidas tendentes a evitar o suprimir las causas que pudieran dañar la muralla y, por otra, tenia la obligación de mantener la muralla de su titularidad en estado adecuado, por lo que la acumulación de agua y la falta de drenaje eran circunstancias susceptibles de dañar la muralla y contribuyeron, aunque no de forma exclusiva, a su derrumbe.

Es evidente que la cuestión descrita obliga, de este modo, a un análisis casuístico de la entidad o alcance de las diversas responsabilidades, sobre la base de los deberes concurrentes y a fin de identificar en qué medida deberá cada uno de los entes contribuir al pago de las indemnizaciones.

No obstante, además de aquella responsabilidad concurrente proclamada sobre la base de un reparto probado y equitativo de culpas, no es posible desconocer que la razón fundamental de tales pronunciamientos radica en una responsabilidad común de todas las administraciones en este ámbito, pues todas, en definitiva, tendrian algo que decir o hacer al respecto.

De ahi que, para terminar, sea preciso destacar la existencia de otros pronunciamientos que, en cualquier caso y sobre la base de tales competencias comunes, concluyen en la existencia de una responsabilidad concurrente, pero solidaria e indistinta, de las diferentes administraciones, que se cohonestaría plenamente con la naturaleza común de tales competencias y que, además, aportaría un elemento de garantía en orden a la efectiva satisfacción de las indemnizaciones (STS de 17 de octubre del año 2010). 